\title{
MAKALAH LOMPAT TINGGI
}

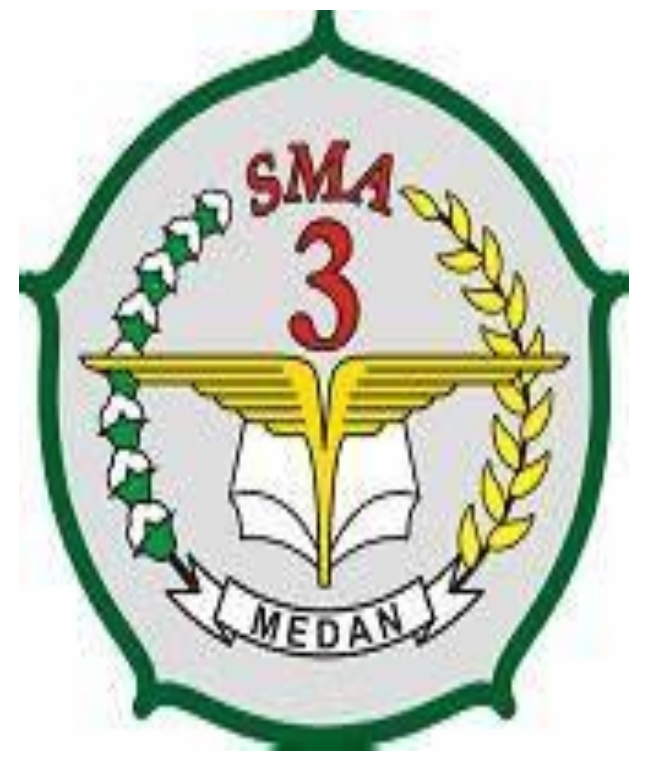

DISUSUN OLEH:

NAMA : CINDY FAZILA

KELAS : X MIA 3

SMA NEGERI 3 MEDAN

JL BUDI KEMASYARAKATAN NO 3,MEDAN. 


\title{
BAB I
}

\begin{abstract}
ABSTRAK
Tujuan Penelitian ini untuk meningkatkan hasil belajar Lompat Tinggi melalui pendekatan perrminan dan olahraga yang dimodifikasi pada yang ditandai siswa dalam mengikuti pembelajaran dan peningkaran hasil tes unjuk kerja.

Penelitian ini menggunakan metode Penelitian Tindakan Kelas. Proseour penelitian ini.jmeliputi planning, acting, observasi dan reflecting. lnstrumen yang digunakan untuk mengambil data pada penelitian ini adalah lembar pengamatan, angket dan tes unjuk kerja siswa. Proses pembelajaran lompat tinggi melalui pendekatan permainan dan olahraga yang dimodifikasi didapat dari sumber data berdasarkan keadaan siswa, alat pembelajaran yang digunakan, sikap siswa saat menggunakan mistar miring, teknik yang
\end{abstract}

\section{A. PENDAHULUAN}

Lompat tinggi termasuk salah satu nomor dalam cabang olahraga atletik.Lompat tinggi itu sendiri adalah salah satu keterampilan untuk melewati mistar yang berada di kedua tiangnya.Tujuan dari lompat tinggi adalah mendapatkan lompatan yang setinggi mungkin.Ketinggian lompatan yang di capai oleh seorang pelompat terhantung dari kemampuan dan persiapan bertanding dari masing - masing atlit. Hingga saat ini,ada dua gaya yang di kenal dalam lompat tinggi,yakni gaya guling perut ( straddle ) dan gaya flop.Gaya Stradle adalah gaya dimana ketika badan melewati mistar dengan cepat diputar dan dibalikkan,sehingga sikap badan di atas mistar telungkup.

Dalam dunia olahraga, dikenal banyak sekali cabang olahraga, antara lain adalah atletik, permainan, senam dan beladiri. Dari keempat cabang olahraga tersebut, atletik mempunyai peranan penting, karena gerakan-gerakannya merupakan gerakan dasar bagi cabang olahraga lainnya. Atletik menurut Aip Syarifuddin (1992 :2) berasal dari bahasa Yunani, yaitu Athlon yang artinya pertandingan, perlombaan, pergulatan atau perjuangan, sedangkan orang yang melakukannya dinamakan Athleta (Atlet). Dengan demikian dapatlah dikemukakan, bahwa atetik adalah salah satu cabang yang dipertandingkan atau diperlombakan yang meliputi atas nomor-nomor jalan, lari, lompat dan lempar.

Atletik merupakan dasar untuk melakukan bentuk-bentuk gerakan yang terdapat didalam cabang olahraga yang lainnya. Dengan mengikuti kegiatan latihan atletik, akan dapat diperoleh berbagai pengalaman yang sangat berguna dan bermanfaat bagi kehidupan, karena 
didalam melakukan kegiatan atletik akan dilatih kekuatan, kecepatan, kelentukan, kelincahan, ketepatan, daya tekan, koordinasi gerak, keuletan, kedisiplinan dan percaya diri serta bertanggung jawab (Aip Syarifuddin dan Muhadi, 1992/1993 : 60).

Masyarakat Indonesia, dalam era globalisasi ini tidak dapat menghindar dari arus derasnya kompleksitas perubahan (Inovasi) sebagai akibat canggihnya teknologi informasi, telekomunikasi , tatanan ekonomi dunia yang mengarah pada pasar bebas,serta tingkat efisiensi dan kompetitif yang tinggi di berbagai bidang kehidupan. Suka/ tidak suka, mau/tidak bangsa Indonesia harus mengikutinya jika tidak akan ketinggalan dan mungkin disebut Negara "primitif"

Globalisasi adalah suatu proses tatanan sosial yang mendunia dan tidak berbatas atau tak mengenal batas wilayah. Globalisasi adalah suatu proses dari gagasan yang sengaja dicari dan dimunculkan, kemudian ditawarkan untuk diikuti oleh bangsa lain yang akhirnya sampai pada suatu titik kesepakatan bersama dan menjadi pedoman bersama bagi bangsa- bangsa di seluruh dunia. (Menurut Edison A. Jamli dkk.Kewarganegaraan.2005)

Menurut pendapat Krsna (Pengaruh Globalisasi Terhadap Pluralisme Kebudayaan Manusia di Negara Berkembang.internet.public jurnal.september 2005). Sebagai proses, globalisasi berlangsung melalui dua dimensi dalam interaksi antar bangsa, yaitu dimensi ruang dan waktu. Ruang makin dipersempit dan waktu makin dipersingkat dalam interaksi dan komunikasi pada skala dunia. Globalisasi berlangsung di semua bidang kehidupan seperti bidang ideologi, politik, ekonomi, sosial budaya, pertahanan keamanan dan lain- lain. Oleh karena itu globalisasi tidak dapat kita hindari kehadirannya.Kehadiran globalisasi tentunya membawa pengaruh bagi kehidupan suatu negara termasuk Indonesia.Pengaruh tersebut meliputi dua sisi yaitu pengaruh positif dan pengaruh negatif.

\section{B. RUMUSAN MASALAH}

Adapun beberapa permasalahan berdasarkan latar belakang di atas yang akan dibahas adalah sebagai berikut :

1. Sejarah lompat tinggi

2. Pengertian lompat tinggi 
3. Peraturan dalam permainan lompat tinggi

4. Teknik-teknik dalam permainan lompat tinggi

5. Media dalam permainan lompat tinggi

\section{TUJUAN MAKALAH}

Adapun beberapa tujuan berdasarkan rumusan masalah di atas yang hendak dicapai adalah sebagai berikut :

1. Mengetahui sejarah lompat tinggi

2. Mengetahui pengertian lompat tinggi

3. Mengetahui peraturan dalam permainan lompat tinggi

4. Mengetahui teknik-teknik yang digunakan dalam permainan lompat tinggi

5. Mengetahui sarana dan prasarana yang digunakan dalam permainan lompat tinggi

\section{BAB II}

\section{PEMBAHASAN}

\section{A. KAJIAN TEORI}

Sejarah Lompat Tinggi

Lompat tinggi bermula dari olimpiade pada abad ke-19 di Skotlandia. Pada kala itu, para peserta lompat tinggi menggunakan gaya gunting dan tercatat lompatan tertinggi yang dilakukan oleh peserta adalah 1,68 meter. Pada saat itu juga, lompat tinggi tidak dilakukan secara sembarangan. Ada gaya-gaya tertentu yang harus dikuasai agar peserta terhindar dari kecelakaan. Pada abad ke-19, peserta lompat tinggi mendarat dan jatuh di atas tanah yang berumput dengan gaya gunting (dengan cara membelakangi) yang ternyata banyak mengakibatkan cedera bagi para peserta. 
Kemudian pada sekitar abad ke 20, gaya lompat tinggi telah dimodernisasi oleh seorang warga Irlandia-Amerika bernama Michael Sweeney. Pada tahun 1895, Michael Sweeney berhasil melakukan lompatan setinggi 1,97 meter gaya eastern cut-off, dimana mengambil off seperti gunting, tapi memperpanjang punggungnya dan mendatar di atas bar.

Warga Amerika lainnya bernama George Horine mengembangkan teknik lompat yang lebih efisien bernama Western Roll. Melalui teknik ini, Horine bisa mencapai lompatan setinggi 2,01 meter pada tahun 1912. Kemudian pada Olimpiade Berlin tahun 1936, teknik lompatan ini menjadi dominan dilakukan sehingga Cornelius Johnson berhasil menang dengan mencapai ketinggian $2.03 \mathrm{~m}$.

Kemudian pada empat dekade berikutnya, pelompat Amerika dan Soviet telah merintis evolusi teknik straddle. Charles Dumas adalah orang pertama yang menggunakan teknik ini mencapai ketinggian 2,13 m pada tahun 1956. Kemudian warga Amerika, John Thomas meningkatkan rekor dunia dengan ketinggian lompatan $2.23 \mathrm{~m}$ pada tahun 1960. Dan akhirnya Valeriy Brumel mengambil alih pencapaian dalam empat tahun ke depan. Pelompat Soviet ini mencatat ketinggian lompatan hingga 2,28 $\mathrm{m}$ dan berhasil memenangkan medali emas pada olimpiade tahun 1964, sebelum kecelakaan sepeda motor mengakhiri karirnya.

Dari Brumel inilah para atlet lompat tinggi mencoba belajar dan mengembangkan olahraga lompat tinggi hingga saat ini terdapat berbagai gaya dalam olahraga lompat tinggi di dunia, antara lain gaya gunting (Scissors), gaya guling sisi (Western Roll), gaya guling (Straddle) dan gaya fosbury flop. Sementara kini, lompat tinggi dilakukan dengan mendarat di atas matras sehingga kecelakaan dapat diminimalisir. Atlet lompat tinggi sekarang banyak menggunakan gaya fosbury flop.

\section{Pengertian Lompat Tinggi}

Lompat tinggi adalah olahraga yang menguji ketrampilan melompat melewati tiang mistar. Lompat tinggi merupakan salah satu bagian dari cabang olahraga atletik. Tujuan lompat tinggi adalah untuk memperoleh lompatan setinggi-tingginya saat melewati mistar tersebut dengan ketinggian tertentu. Tinggi tiang mistar yang harus dilewati pelompat minimal 2,5 meter, sedangkan panjang mistar minimal 3,15 meter. Lompat tinggi dilakukan di arena lapangan atletik dan tanpa bantun alat. 
Lompat tinggi termasuk dalam cabang olahraga atletik. Menurut Aip Syarifuddin, atletik berasal dari bahasa Yunani, Athlon, yang artinya pertandingan, perlombaan, pergulatan, atau perjuangan. Dengan demikian dapat diartikan bahwa cabang olahraga meliputi nomor-nomor jalan, lari, lompat, dan lempar. Atletik merupakan dasar untuk melakukan bentuk-bentuk gerakan yang terdapat di dalam cabang olahraga lainnya. Dengan mengikuti olahraga atletik, akan diperoleh berbagai pengalaman yang sangat berguna dan bermanfaat bagi kehidupan karena melatih kekuatan, kecepatan, kelentukan, kelincahan, ketepatan, daya tekan, koordinasi gerak, keuletan, kedisiplinan, dan percaya diri, serta bertanggung jawab.

\section{Peraturan Lompat Tinggi}

Sebelum perlombaan dimulai, ketua juri harus mengumumkan kepada segenap peserta lomba mengenai tinggi mistar permulaan dan tinggi berikutnya. Mistar lompat akan dinaikkan pada akhir tiap babak/ronde sampai hanya tersisa satu orang peserta lompat tinggi yang memenangkan perlombaan, atau terjadi hasil sama untuk kedudukan pertama. Apabila terjadi hasil sama, pemenang dilihat dari kegagalan terkecil selama perlombaan dan ketinggian yang terakhir yang dilewatinya.

Dalam pertandingan, mistar akan dinaikkan setelah pelompat berhasil melewati ketinggian mistar. Pelompat boleh mulai melompat pada ketinggian permulaan yang disukainya dengan ketinggian minimal 2,5 m. Lompatan dianggap batal apabila pelompat menyentuh palang atau tidak melompat. Pelompat yang menjatuhkan palang atau menyentuh tanah termasuk daerah pendaratan di balik bidang tegak dari sisi dengan lebih dekat tiang lompat, baik itu diantara atau di luar tiang lompat dengan salah satu bagian dari tubuhnya, tanpa pertama kali melewati mistar lompat dianggap gagal.

Setiap pelompat akan diberi peluang sebanyak tiga kali untuk melakukan lompatan. Jika pelompat tidak berhasil melewati mistar sebanyak tiga kali berturut-turut, dia dinyatakan gagal. Untuk menentukan kemenangan, para pelompat harus berusaha melompat setinggi 
mungkin yang dapat ia lakukan. Pemenang ditentukan dengan lompatan tertinggi yang dilewati.

\section{Teknik Lompat Tinggi}

Dalam permainan lompat tinggi, dibutuhkan penguasaan akan teknik-teknik yang ada guna mencapai hasil yang maksimal atau hasil yang diharapkan. Ada empat jenis gaya lompat tinggi yang umumnya digunakan oleh peserta lompat tinggi, antara lain sebagai berikut.

\section{Teknik Gaya Guling (Straddle)}

Gaya guling (Straddle) merupakan gaya dimana badan kita melewati tiang dengan cara diputar dan dibalikkan lagi sehingga sikap badan kita saat di atas mistar tertelungkup. Cara untuk melakukan gaya guling adalah pelompat harus mengambil awalan terlebih dahulu dari samping antara 3, 5, 7, atau 9 langkah. Tumpuan terletak pada kaki yang paling kuat, kemudian ayunkan ke depan. Setelah kaki diayunkan, dengan cepat badan kita balikkan untuk bisa melewati mistar sehingga sikap badan kita di atas mistar telungkup. Pantat kita usahakan lebih tinggi dari kepala kita, jadi kepala agak menunduk. Pada waktu mendarat gunakan kaki kanan dan tangan kanan jika tumpuan menggunakan kaki kiri, begitu pula sebaliknya.

Cara lainnya adalah dengan mengambil jarak awalan dari samping antara 4, 6, 8, atau 10 langkah tergantung pada ketinggian target yang ingin dilewati. Jika meng-gunakan kaki kiri sebagai tumpuan, ayunkan kaki kanan ke belakang menuju depan. Setelah kaki ayunan melewati mistar, kemudian posisi badan saat di udara atau di atas mistar dalam keadaan tengkurap. Posisi pinggang usahakan lebih tinggi dibandingkan dengan posisi kepala. Ketika posisi terjatuh, tumpuan berada di kedua tangan dan kaki ayunan yang pertama mendarat, lalu dilanjutkan dengan meng-gulingkan badan yang pertama (bagian punggung tangan) dan berakhir pada bahu.

Teknik awalan yang digunakan untuk teknik Straddle adalah mengambil posisi ancangancang yang tidak terlalu jauh, berlari dengan kecepatan sedang, posisi awalan dari samping sekitar $30^{\circ}$ atau $40^{\circ}$ dengan posisi tiang lompatan, dan berlari agak serong dari mistar; sedangkan teknik tolakan Straddle adalah menggunakan tumpuan kaki yang tersekat dengan mistar, posisi badan agak merebah atau sedikit condong ke belakang ketika akan melakukan tolakan, posisi kaki tumpuan menolak ke atas hingga kedua lutut kaki lurus dan kedua tangan 
dan kaki diayunkan dengan tenaga penuh ke depan. Teknik Straddle saat di atas mistar adalah posisi badan tengkurap dan posisi kaki harus segera diluruskan ke belakang ketika badan sudah mulai turun; sedangkan teknik mendarat Straddle adalah jika menggunakan tumpuan kaki yang kiri, maka posisi pendaratan memakai kaki kanan terlebih dahulu yang kemudian dilanjutkan dengan gerakan posisi berguling.

\section{Gaya Fosbury Flop}

Gaya ini diciptakan oleh Dick Ricarod Fosbury yang merupakan seorang pelompat tinggi dari Amerika Serikat. Keunikan dari gerakan Fosbury adalah tubuh berada di atas mistar dengan posisi terlentang dan jatuh menggunakan punggung yang masih dalam kondisi terlentang. Teknik ini merupakan kebalikan dari teknik Straddle, yakni punggung yang menghadap ke bagian bawah arah agak serong ke kiri, tidak lagi tegak lurus pada mistar.

Teknik awalan untuk gaya Flop adalah arahan dari depan, tegak lurus menghadap mistar. Jika menggunakan kaki kiri sebagai tumpuan, dari depan menuju tiang sandaran mistar sebelah kanan. Teknik tolakan untuk gaya Flop adalah menggunakan kaki terkuat pada tumpuan. Bila menggunakan kaki kiri, diangkat dengan lutut kaki ditekuk bersamaan dengan memutar badan ke arah awalan. Badan harus membelakangi mistar dan punggung berada di bagian bawah yang dekat dengan mistar dengan posisi punggung melengkung saat melewati mistar.

Teknik Flop saat di atas mistar adalah bagian kepala harus lebih dahulu melewati mistar dengan posisi badan yang terlentang dan punggung menghadap ke bawah arah mistar. Saat mencapai ketinggian yang maksimal dan pinggang melewati mistar, posisi kedua kaki digerakan atau diayun ke atas agar bisa melewati mistar dengan sempurna. Untuk pendaratan, bagian tubuh yang mendarat terlebih dahulu adalah punggung karena sikap tubuh yang terlentang saat melakukan pendaratan dan hanya boleh dilakukan dengan pendaratan pada bahan berbahan busa.

\section{Gaya Gunting (Scissors)}

Gaya ini ditemukan oleh Sweney, oleh karena itu juga sering disebut dengan Gaya Sweney. Sebelumnya di tahun 1880, Sweney menggunakan gaya jongkok, namun ia merasa gaya tersebut kurang tepat hingga akhirnya beliau mengubah gaya tersebut menjadi gaya gunting 
pada tahun 1896. Cara melakukan gaya gunting adalah mula-mula pelompat mengambil awalan dari tengah. Bila pelompat pada saat akan melompat menggunakan kaki kiri sebagai tumpuan lalu memakai kaki kanan sebagai ayunan, maka ia mendarat (jatuh) dengan kaki kanan juga.

\section{Gaya Guling Sisi (Western Roll)}

Gaya ini diciptakan oleh G. Horin yang berasal dari Amerika pada tahun 1912, namun gaya ini tidak dapat berkembang karena ada benturan dengan peraturan yang berlaku, dimana lompat tinggi menggunakan gaya guling sisi membuat posisi kepala cenderung lebih rendah dari pinggul kita saat kita melewati mistar, sehingga hal ini tidak sah. Oleh karena itu, gaya ini tidak pernah digunakan dalam lompat tinggi.

\section{Sarana dan Prasarana Lompat Tinggi}

\section{Tiang dan Mistar Lompat}

Tiang dan mistar yang digunakan dalam permainan lompat tinggi harus memenuhi beberapa ketentuan. Semua bentuk dan model tiang lompat dapat digunakan asalkan kaku dan kekar. Tiang memiliki penopang yang kaku dan kokoh untuk mistar, serta haruslah cukup tinggi untuk melebihi tiang sebenarnya terhadap mana mistar lompat dinaikkan dengan minimum $10 \mathrm{~cm}$. Jarak antara tiang lompat harus tidak kurang dari $4 \mathrm{~m}$ juga tidak melebihi dari 4,04 m. Tiang lompat/tiang harus tidak dipindah selama perlombaan berlangsung kecuali bila wasit memikirkan bahwa apakah tempat bertumpu atau pendaratan menjadi tidak sesuai lagi.

Mistar dapat dibuat dari metal atau kayu, berbentuk bulat atau segitiga dengan diameter minimum 2,5 cm dan maksimum $3 \mathrm{~cm}$, dengan permukaan yang datar atau rata pada kedua ujung yang berguna untuk meletakkan pada papan penopang. Panjang mistar minimal 3,64 $\mathrm{m}$ dan maksimal $4 \mathrm{~m}$, berat maksimal $2 \mathrm{~kg}$. Mistar lompat harus terbuat dari fiberglass atau materi atau bahan lain yang cocok namu bukan dari metal, bagian tengahnya/potongan melintangnya bulat silindris kecuali pada kedua ujung mistar. Garis tengah/diameter pada 
bagian mistar yang bulat silindris haruslah 30mm. Ujung mistar lompat harus terletak di atas sedemikian rupa sehingga bila mistar disentuh oleh pelompat akan dengan mudah jatuh ke tanah, baik di depan maupun di belakang.

\section{Matras (Tempat Pendaratan)}

Tempat pendaratan lompat tinggi harus memenuhi ketentuan, yakni tidak boleh kurang dari 3 x $5 \mathrm{~m}$ yang terbuat dari busa dengan ketinggian $60 \mathrm{~cm}$ dan di atasnya ditutupi oleh matras yang tebalnya $10-20 \mathrm{~cm}$ dengan warna terserah.

\section{Lapangan Lompat Tinggi}

Lapangan lompat tinggi terdiri atas tiga bagian, yakni jalur ancang-ancang, tempat/area bertolak, dan tempat pendaratan. Daerah awalan (jalur ancang-ancang) panjangnya tidak terbatas dengan minimum $15 \mathrm{~m}$, daerah tumpuan (tempat bertolak) harus datar dan tingkat kemiringanya $1: 100$, sedangkan tempat pendaratan harus dilengkapi dengan matras agar pelompat tidak cedera.

\section{BAB III}

\section{PENUTUP}

\section{A. KESIMPULAN}

Dari uraian di atas, dapat ditarik kesimpulan bahwa lompat tinggi merupakan olahraga melompat setinggi mungkin dengan melewati mistar lompat. Permainan lompat tinggi membutuhkan tempat yang tidak terlalu luas untuk memainkannya dan dapat dilakukan oleh pria maupun wanita. Dalam permainan lompat tinggi, diperlukan penguasaan berbagai teknik/gaya melompat guna tercapainya hasil yang maksimal dan sesuai harapan, yakni meraih lompatan tertinggi. Selain itu, juga terdapat beberapa ketentuan yang harus dipatuhi dan hal-hal yang perlu diperhatikan agar tidak terdiskualifikasi atau kalah. 


\section{B. DAFTAR PUSTAKA}

https://zuliaden-jayus.blogspot.com/2014/08/makalah-lompat-tinggi.html

https://vita-project.blogspot.com/2018/05/makalah-lompat-tinggi.html

https://digilib.uns.ac.id/dokumen/abstrak/71684/Meningkatkan-Hasil-Belajar-Lompat-

Tinggi-melalui-Pendekatan-Permainan-dan-Olahraga-yang-Dimodifikasi-pada-Siswa-Kelas$\underline{\text { IV-Sekolah-Dasar-Negeri-1-Karangnangka-Mrebet-Purbalingga-Tahun-Pelajaran-20122013 }}$ 